\title{
Estudo crítico sobre as propostas de alteração do direito do trabalho: tratamento diferenciado aos empregados de microempresas e de empresas de pequeno porte é constitucional e necessário?
}

\author{
Fabiana Keylla Schneider ${ }^{1}$ \\ Lourival José de Oliveira ${ }^{2}$
}

\begin{abstract}
Resumo
Desmistificou-se o entendimento acerca da supressão de direitos trabalhistas daqueles que laboram junto às micro e pequenas empresas enquanto sendo o único caminho para a geração de empregos formais no Brasil e fortalecimento de ditas empresas. Micro e pequenos empreendimentos e seus empregados muito se aproximam quanto à caracterização: igualmente frágeis, recebendo, por isso, tratamento diferenciado e protetivo na Constituição Federal. Em razão dessas diretrizes, para que seja implementada a política de apoio ao micro e pequeno empresariado, muitas alternativas mostram-se adequadas, não sendo necessário, para tanto, subtrair direitos dos trabalhadores. Destarte, concluiu-se ser possível que o Estado adote uma postura ativa em prol das micro e pequenas empresas por meio de ações afirmativas, com o fito de incentivá-las a crescer, sem, desta forma, criar o "empregado de segunda linha", que feriria frontalmente o princípio da igualdade. Agindo assim, é possível alcançar o desenvolvimento econômico, seguindo os ditames constitucionais para a construção de uma sociedade justa e solidária e valorizando-se o trabalho humano, em respeito ao princípio da dignidade da pessoa humana.
\end{abstract}

Palavras-Chave: Ações afirmativas; Hipossuficiência do trabalhador; Micro e pequenas empresas; Princípio da proteção.

\section{Introdução}

As microempresas e empresas de pequeno porte, importante setor da economia nacional e constitucionalmente protegidas, para se desenvolverem no competitivo mercado brasileiro precisam de proteção e auxílio Estatal. Inúmeras são as adversidades enfrentadas pelas mesmas, sendo uma delas o cumprimento da legislação trabalhista. Para se garantir o desenvolvimento destas empresas e assegurar-lhes tratamento favorecido seria necessário suprimir direitos trabalhistas dos empregados daquelas? Existiriam outras medidas eficazes

Acadêmica do 5ㅇa ano matutino do curso de Direito da Universidade Estadual de Londrina.

Doutor em Direito (PUC-SP); professor adjunto da Universidade Estadual de Londrina; professor da UNOPAR; professor da FACCAR; professor da UNIMAR. 
que garantiriam um tratamento mais benéfico aos micro e pequenos empreendimentos, de modo a auxiliá-los a crescer e se fortalecerem?

É sobre este enfoque que o presente trabalho se desenvolve, na medida em que busca explicitar a estrutura, importância e necessidades das micro e pequenas empresas, bem como a hipossuficiência do trabalhador, em vistas a se buscar alternativas que assegurem os direitos constitucionalmente conferidos aos citados empregadores e seus empregados.

\section{Microempresas e empresas de pequeno porte}

As micro e as pequenas empresas surgiram com o próprio comércio, se fortaleceram com o artesanato e com as corporações de ofício, ganhando, aos poucos, uma roupagem própria e reconhecimento. Com o passar dos anos, esse setor foi se fortalecendo e se tornando em um dos segmentos mais importantes da economia, tendo, na mesma proporção, um papel social fundamental. E, é em razão desta atuação que se tem dedicado cada vez mais atenção às empresas de micro e pequeno porte.

A grande conquista destas empresas, em matéria legislativa, deu-se com a edição da Constituição Federal, de 5 de outubro de 1988, que estabeleceu a proteção às micro e pequenas empresas incluindo em seu bojo "a ordem econômica fundada na valorização do trabalho humano e na livre iniciativa" (CF, art. 170), sendo um de seus princípios o "tratamento favorecido para as empresas de pequeno porte" (inciso XI).

Qual a razão para a referência às empresas de pequeno porte? Nos dizeres de Ana Maria Benedito Duarte e Denise Perissini da Silva (2001, p. 15-16):

Porque o legislador constitucional entendeu que elas são uma realidade cada vez mais presente no País, através da geração de empregos, captação de rendimentos e circulação de bens e serviços. Por isso, são consideradas responsáveis por uma parcela significativa do desenvolvimento econômico brasileiro. Mas, por suas características próprias de estrutura reduzida e atividade simplificada, não poderiam receber o mesmo tratamento tributário que aquele dispensado às grandes empresas, que apresentam, essencialmente, uma estrutura e atividade mais complexas, sem que tal diferenciação constitua privilégio ou discriminação, práticas vedadas pela própria Constituição.

O tratamento diferenciado às microempresas e empresas de pequeno porte nada mais significa que a aplicação de normas desiguais aos que assim o são. Isso, logicamente, 
Estudo crítico sobre as propostas de alteração do direito do trabalho: tratamento diferenciado aos empregados de microempresas e de empresas de pequeno porte è constitucional e necessário?

não afeta o princípio da igualdade, pelo contrário, o faz consubstanciar-se, pois em se tratando de pessoas desiguais, merecido o trato diferido para corrigir a distorção marcante entre empresas de portes tão variados.

Inúmeras leis infraconstitucionais seguiram as diretrizes da Constituição Federal, inovando em benefício das microempresas e das empresas de pequeno porte com resultados extremamente positivos no que tange à formalização de empresas e postos de trabalho. ${ }^{3} \mathrm{E}$, em atendimento às novas necessidades impostas às micro e pequenas empresas, em 2006 foi promulgada a Lei Complementar no. 123, de 14 de dezembro de 2006, apelidada de Lei Geral da Micro e Pequena Empresa, ou Super Simples.

Em suma, a legislação em vigor, destacadamente a Constituição Federal, dá azo à criação de um ambiente que propicie maiores facilidades, ou melhor, menores dificuldades, à criação e desenvolvimento do micro e pequeno empresariado, inclusive no que se refere à matéria trabalhista, por se tratar de um setor estratégico da política econômica e social, como será demonstrado.

As tentativas e efetivas atitudes para melhorar a atuação das pequenas e microempresas existem. Contudo ainda não satisfazem às exigências que se impõem. Por certo ainda há muito a ser feito, o caminho é longo e as adversidades são incontáveis, sem falar na eterna dependência da vontade política e atualização da visão jurídica com relação à questão aqui debatida.

Uma das iniciativas que ainda se aguarda é a criação de um Simples Trabalhista, com a promessa de trazer enormes vantagens tanto para empregadores quanto para empregados, aumentar o número de empregos formais e reduzir o crescente desemprego que assola o Brasil.

Entretanto, cuida-se, oportunamente, para que a criação destas normas não seja fonte de empregados que poderiam ser designados de "segunda linha", como se verá mais adiante. Tudo em atenção aos ditames da justiça social.

\footnotetext{
“Cechim e Fernandes realizaram um estudo de acompanhamento da formalização das micro e pequenas empresas a partir da aprovação do SIMPLES (Cechim e Fernandes, 2000). Foram acompanhadas 1.128.219 empresas existentes em janeiro de 1996 que, potencialmente, se enquadrariam no SIMPLES. Em 1996, antes da aprovação da referida lei, esse conjunto de empresas empregou 773 mil pessoas com carteira assinada. O SIMPLES entrou em vigor em janeiro de 1997. Um ano depois, aquelas empresas empregaram 1.314.000 trabalhadores com carteira assinada - um aumento de 70\%. Em 1999, cerca de 1 milhão de empresas haviam optado pelo SIMPLES e o número de empregados formais subiu para 3,5 milhões!" (PASTORE, 2005).
} 


\subsection{Conceito, características, situação atual e novas perspectivas}

Não se pode negar que as micro e pequenas empresas são importantes fontes produtoras de recursos e captadoras de mão-de-obra nos setores do comércio, da indústria e da prestação de serviços. ${ }^{4}$

Mas, como caracterizar e definir essas tão faladas empresas? Elas possuem peculiaridades que as diferem das demais, e a partir destas características, a lei pautou-se para estabelecer conceitos objetivos.

As micro e as pequenas empresas, na forma sintetizada por Carlos Montaño (2001, p. 15), apresentam uma estrutura muito elementar: são pequenas, com poucos trabalhadores, baixo volume de produção e comercialização, com insuficiente desenvolvimento tecnológico e reduzido mercado e raio de incidência, portanto, menos lucrativas; são também pouco complexas, altamente centralizadas, com pouca estratificação e escassa divisão de tarefas. Enfim, consiste em uma categoria socioeconômica particular.

O conceito objetivo destas empresas é trazido pela legislação infraconstitucional, notadamente, art. 3ㅇ da Lei Complementar n‥ 123/2006, que utiliza como parâmetro de definição a receita bruta anual da empresa.

A despeito do conceito estritamente legal, há que se vislumbrar a micro e a pequena empresa como parte de uma reestruturação produtiva que se mostra como alternativa ao desemprego, dada sua relevante presença quantitativa, absorvendo grandes massas de trabalhadores com reduzido grau de qualificação (MONTAÑO, 2001, pp. 25-26).

Por fim, há que se caracterizar o empresário ${ }^{5}$, o sócio da micro e da pequena empresa. Em síntese, o empresário de um micro ou pequeno empreendimento é proprietário dos meios de produção, explora força de trabalho, mas não realiza uma acumulação ampliada suficiente para se capitalizar, participando efetivamente na produção com sua própria força de trabalho. Por assim dizer, esse tipo de empresário possui um cunho

\footnotetext{
4 “A geração de empregos nas empresas formais alcançava o total de 27.561.924 ocupações em 2002, representando $42 \%$ de toda a população economicamente ativa no meio urbano. Daquele total, $57,2 \%$ estavam empregadas em micro e pequenas empresas, alcançando 15.757 .076 pessoas. O setor que mais emprega nas microempresas é o comércio, que ocupava 58,9\% dos empregos nesse setor. O segundo setor que mais gera empregos nas microempresas é o de serviços, com 28,8\% do total setorial." (SEBRAE, 2004).

5 Para os limites deste trabalho, será usada a expressão "empresário" para denominar o sócio, o proprietário da empresa, o empreendedor, apesar de não ser esta a correta denominação, mas apenas como forma de facilitar o entendimento do texto.
} 
Estudo crítico sobre as propostas de alteração do direito do trabalho: tratamento diferenciado aos empregados de microempresas e de empresas de pequeno porte è constitucional e necessário?

mais fortemente trabalhador do que capitalista, tem uma identidade socioeconômica que mais se assemelha a dos trabalhadores assalariados, que propriamente a um empresário.

$\mathrm{Na}$ grande maioria dos casos, tais empresários também possuem nível de escolaridade próximo ao do próprio trabalhador, com poucos conhecimentos nas áreas contábil, administrativa, e claro, jurídica.

Tomar providências no sentido de incentivar o desenvolvimento das empresas de micro e pequeno porte é papel do Estado, no intuito de proteger o próprio mercado de trabalho e garantir a construção de uma sociedade mais justa, bem como o desenvolvimento nacional, objetivos fundamentais da República Federativa do Brasil.

\section{Hipossuficiência do trabalhador}

Partindo-se do pressuposto de que o trabalhador encontra-se em nível hierarquicamente abaixo do empregador, como sendo seu subordinado, o Direito do Trabalho surge como instrumento de proteção do mais fraco, de forma a aplicar normas desiguais aos desiguais. Com o mesmo entendimento, bem definiu Américo Plá Rodriguez (2000, p. 80):

Todo o Direito do Trabalho nasceu sob o impulso de um propósito de proteção. Se este não tivesse existido, o Direito do Trabalho não teria surgido. Surgiu com o preciso objetivo de equilibrar, com uma desigualdade jurídica favorável, a desigualdade econômica e social que havia nos fatos.

Assim, surgiram os princípios e as normas de proteção ao trabalhador, sendo aqueles as diretrizes de todo conjunto normativo do Direito do Trabalho. $E$, em que pese a iniludível relevância de todos os princípios existentes no Direito do Trabalho, destacam-se: da aplicação da norma mais favorável e o princípio do in dúbio, pro operário, corolários do princípio da proteção ao trabalhador.

Não se nega a necessária proteção ao trabalhador. Tampouco a supressão dos princípios protetivos. Contudo, tendo-se em vista as evoluções no próprio Direito do Trabalho, não se deve dar um alcance excessivamente amplificado aos mesmos, no sentido de considerar todo o Direito do Trabalho como protetor ao empregado. A intenção é manter o equilíbrio entre as partes, na proporção em que a fragilidade do trabalhador as separa. 
Quer-se com isso dizer que a desigualdade jurídica deve ser aplicada proporcionalmente às diferenças existentes entre empregador e empregado, de forma a corrigir as distorções criadas pelo próprio sistema capitalista vigente, conforme as circunstâncias a exigirem.

Assim, os princípios de proteção ao trabalhador devem guinar-se a normalizar as relações entre empregados e empregadores de forma a assegurar a paz social, o equilíbrio entre as partes, acompanhando as mudanças sofridas pela economia e pela política, que se refletem no mercado de trabalho e na cultura geral da população. Certas modificações devem ser admitidas em nome da eficiência da produção que gera efeitos benéficos para todos, inclusive aos próprios trabalhadores, almejando-se garantir benefícios mínimos que caracterizam as regras trabalhistas, mas com vistas a atender aos reclames do próprio mercado de trabalho.

\subsection{Amparo constitucional ao trabalhador}

A Constituição Federal traz uma série de direitos favoráveis aos trabalhadores, estabelece inúmeras garantias mínimas a serem observadas, notadamente no art. 7oㅡ, que, para muitos autores, "vem a ser uma verdadeira CLT, tantos os direitos trabalhistas nele albergados" (MARTINS, 2004, p. 44). A crítica também é feita por José Afonso da Silva (2004, p. 292): “A Constituição não é o lugar para se estabelecerem as condições das relações de trabalho, mas ela o faz, visando proteger o trabalhador, quanto a valores mínimos [...]".

Tendo-se em vista tais "cláusulas principiológicas", fácil concluir o "tratamento peculiar" conferido pela Constituição Federal ao "trabalho e seus agentes (os trabalhadores)", nas expressões de Eros Grau (2005, p. 198), que completa: "Esse tratamento, em uma sociedade capitalista moderna, peculiariza-se na medida em que o trabalho passa a receber proteção não meramente filantrópica, porém politicamente racional".

Em resumo, o tratamento constitucional cominado aos trabalhadores expressa a prioridade dos valores do trabalho sobre os demais valores da economia de mercado, que culmina na valoração social do trabalho (SILVA, 2004, p. 768).

Todavia, apesar da Constituição Federal e da legislação infraconstitucional garantirem direitos aos trabalhadores para que os mesmos vivam com dignidade, ainda não 128

ReVista de Direito Público, LondRINA, V. 2, N. 2, P. 123-142, MAIO/Ago. 2007. 
Estudo crítico sobre as propostas de alteração do direito do trabalho: tratamento diferenciado aos empregados de microempresas e de empresas de pequeno porte è constitucional e necessário?

se vislumbra esse quadro, a realidade está bem longe daquela idealizada pela Carta Maior. Tem-se buscado que as pessoas possam, ao menos, ter um emprego. Contudo, as taxas de desemprego ${ }^{6}$ ainda são bastante desanimadoras.

Em que pese todo o protecionismo conferido aos trabalhadores, que teve o sincero ideal de lhes garantir direitos mínimos para o exercício da cidadania, para o usufruto da dignidade, tem se mostrado precário para tanto. Direitos esses, que para os mais radicais ${ }^{7}$, chegam a ser exacerbados, tolhendo justamente o fim almejado.

\section{Micro e pequenas empresas e o mercado de trabalho}

Resta inquestionável que as microempresas e as empresas de pequeno porte enfrentam várias adversidades para seu estabelecimento: alta carga tributária, legislação trabalhista e previdenciária, concorrência das empresas maiores e das informais, falta de conhecimento dos próprios sócios da empresa. E, em que pese sua fragilidade, devem cumprir praticamente as mesmas obrigações de outras empresas maiores, flagrando evidente desvantagem concorrencial para as menores.

Segundo dados disponibilizados pelo Sebrae (2004), as micro e as pequenas empresas representam 99\% das empresas formais do Brasil e contribuem com aproximadamente $20 \%$ do Produto Interno Bruto. Como se vê, a representatividade das microempresas e empresas de pequeno porte é demonstrada pelos números, que estampam a importância das mesmas para a geração de rendas e empregos.

Em excelentes pesquisa e trabalho realizados pelo Instituto Brasileiro de Geografia e Estatística (IBGE) constatou-se que uma das mais importantes contribuições das micro e pequenas empresas no crescimento e desenvolvimento neste País:

6 Sem a intenção de aprofundar no assunto, importa colacionar os ensinamentos e Ladislau Dowbor: “O próprio conceito de desemprego evolui, na medida em que às medidas clássicas de desemprego temos de acrescentar o desemprego por desalento, o trabalho temporário, novas formas de vinculação com o emprego, a própria perda de interesse e motivação segundo os níveis de remuneração, e segundo novas exigências como a qualidade do trabalho. Colocam-se de maneira nova os problemas articulados da segurança do emprego, da satisfação com o trabalho, da distribuição dos ganhos". (DOWBOR, 2006).

7 Nesse grupo encontra-se o ex-Ministro do Trabalho, Marcelo Pimentel, que em híspidas palavras, desta forma doutrinou: "A CLT é a maior propulsora da violência contra os direitos dos trabalhadores, conseqüência da autodefesa dos empresários, que se vêem tolhidos no progresso dos seus empreendimentos pela soma dos obstáculos que lhe são impostos por uma legislação esdrúxula, superada e inadequada para um País moderno. Não ouso dizer que se deve passar uma borracha por sobre a CLT, tirando-a do mundo jurídico. O que se objetiva é uma reforma da legislação [...]". (PIMENTEL, 2000, p. 172173). 
[...] é a de servirem de 'colchão' amortecedor do desemprego. Constituem uma alternativa de ocupação para uma pequena parcela da população que tem condição de desenvolver seu próprio negócio, e em uma alternativa de emprego formal ou informal, para uma grande parcela da força de trabalho excedente, em geral com pouca qualificação, que não encontra emprego nas empresas de maior porte (IBGE, 2003).

Nesse caminhar, é uníssona a voz daqueles que clamam por uma legislação diferida para as micro e pequenas empresas, ao apontarem, principalmente, a existência de uma legislação trabalhista de "tamanho único" para realidades diferentes. Justificam tal argumento sob o fato das micro e pequenas empresas significarem importantes fontes de geração de emprego e circulação de renda.

\subsection{Reflexos da informalidade no mercado de trabalho}

A solução para problemas como aqueles expostos em itens anteriores é imprescindível para a redução da informalidade das micro e pequenas empresas. A redução de problemas que sufocam estas empresas refletirá, por certo, no mercado de trabalho: quanto maior a informalidade das empresas, maior o número de trabalhadores laborando sem registro em carteira.

É de se dizer que a informalidade contamina diversas áreas, gerando empresas informais, empregos informais e empresas formais com empregados informais. Com isso, o setor formal sofre uma concorrência predatória (SACHS, 2003, p. 28).

Importa destacar que a escassez dos postos de emprego tem como efeito perverso a exclusão social dos trabalhadores, na medida em que só encontram vagas para trabalhar na informalidade.

Apesar dos expressivos incentivos fiscais concedidos às micro e pequenas empresas, notadamente pela Lei no. 9.317/1996 e Lei Complementar №. 123/2006, ainda resta a enorme complexidade e o gigantesco peso das despesas trabalhistas para a contratação formal, notadamente as contribuições sociais.

Contrariamente às empresas de micro e pequeno porte, a maioria das grandes e médias empresas tem condições de pagar essas despesas e os custos das ações trabalhistas. Isso afeta diretamente a competitividade, os novos investimentos e o emprego futuro, em 
Estudo crítico sobre as propostas de alteração do direito do trabalho: tratamento diferenciado aos empregados de microempresas e de empresas de pequeno porte è constitucional e necessário?

evidente prejuízo aos micro e pequenos empresários e, por conseguinte, aos próprios empregados.

O Brasil deve encarar sua realidade caracterizada por uma grande concentração em empresas fracas. Isso impõe restrições ao cumprimento da regulação legislada no campo do trabalho.

Em resumo, dificuldades impostas às micro e pequenas empresas na área trabalhista mostram-se como um dos fatores que pode conduzir à contratação informal ou, o que é pior, ao crescimento do desemprego, ambos altamente prejudiciais ao desenvolvimento do Estado Brasileiro, seja econômica como socialmente falando.

\section{Tratamento diferenciado às micro e pequenas empresas no que tange às obrigações trabalhistas}

No Brasil, o empresário que oferta emprego formal está fadado a sofrer a concorrência daqueles que não o fazem. Isso porque aquele que cumpre regularmente a legislação trabalhista é obrigado a sujeitar-se ao pagamento de inúmeras contribuições sociais, além de cumprir as obrigações trabalhistas previstas na CLT (Consolidação das Leis Trabalhistas) e na Constituição Federal.

Tudo isso resulta em fatos extremamente danosos à economia nacional, pois se cria um círculo vicioso: empresas formais são prejudicadas pela concorrência desleal das empresas informais, podendo, assim, não conseguirem manter-se no mercado, sendo obrigadas a fechar ou se render, também, à informalidade. Ressalte-se que empresas informais não podem contratar formalmente seus empregados.

De fato, as micro e pequenas empresas, principalmente pela falta de aporte jurídico e contábil, encontram dificuldades para cumprir regularmente a legislação trabalhista, onerando-as excessivamente.

Diante desta situação, inúmeros caminhos podem ser tomados. O que se deve verificar é qual deles possibilitará o melhor benefício, submetendo-se ao menor custo. 


\subsection{Micro e pequenos empresários e os trabalhadores}

Retomando a obra de Carlos Montaño (2001, p. 88), no qual o autor faz comparações entre trabalhadores e micro e pequenos empresários, ele afirma

[...] o empresário da PeME, mesmo heterogeneamente, tem no caráter de trabalhador um peso maior que condição de capitalista; ele tem uma identidade socioeconômica que mais se assemelha à dos assalariados; ele está aparentemente mais identificado ao capitalista, mas, em essência, mais próximo do trabalhador.

De tudo o que foi abordado, extrai-se a ilação de que o micro e o pequeno empreendedor muito se aproxima da figura do empregado.

Evidencia-se, pois, a nivelação entre os micro e pequenos empreendedores e seus empregados. Com isso, a aplicação de uma legislação trabalhista altamente protecionista a seus destinatários faz com que a balança penda para um lado, desigualando desfavoravelmente às empresas empregadoras. Diante disso, busca-se medidas compensatórias que retomem o equilíbrio almejado, até para que se garanta a competitividade dessas empresas com as demais.

\subsection{Lei Complementar no. 123, de 14 de dezembro de 2006}

A Lei Geral das Microempresas e das Empresas de Pequeno Porte, introduzida pela Lei Complementar no. 123/2006, possui, como uma de suas principais propostas, o estímulo à formalidade das empresas, objetivando fortalecer as micro e pequenas empresas através do estímulo à formalidade e à geração de empregos. Tais condições benéficas visam compensar as dificuldades enfrentadas pelas empresas destinatárias da lei, oferecendo-lhes vantagens principalmente tributárias.

A grande maioria das disposições contidas no diploma apresenta natureza tributária, visando fomentar a atividade empresarial por meio da redução da carga fiscal e da simplificação das formalidades nesse campo.

Apesar das inovações, paira a dúvida se as vantagens criadas compensarão as obrigações sociais devidas quando houver relação de emprego formal, dentro da CLT. 
Estudo crítico sobre as propostas de alteração do direito do trabalho: tratamento diferenciado aos empregados de microempresas e de empresas de pequeno porte è constitucional e necessário?

\title{
5.3 Simples trabalhista
}

De tudo o que foi dito, resta a apresentação de uma proposta que assegure, ao mesmo tempo, os direitos trabalhistas e os da micro e pequena empresa, de modo a convergir os interesses dos mesmos, em observância à fragilidade inata a eles. Tudo isso para que as citadas empresas possam sustentar-se equilibradamente no concorrente mercado e formalizar e aumentar o quadro empregatício.

Sobre o assunto, a Juíza Dalva de Oliveira (2003, p. 357-365) pondera:

\begin{abstract}
Vê-se que a legislação trabalhista, abundante e generosa, já não cumpre o seu papel. Não é para todos, não é irrenunciável e não protege justamente quem mais dela precisa: o trabalhador desqualificado e hipossuficiente, parte frágil na relação capital-trabalho. [...] a legislação trabalhista e previdenciária há que mudar, porque hoje em dia favorece apenas aqueles empregados que dela não mais precisam: pessoas com bom nível de escolaridade e capacitação profissional, que têm discernimento e competência para atuar politicamente e agir junto a seu sindicato, mas que não o fazem simplesmente porque não precisam, porque o Estado já regulamenta fartamente seu trabalho.
\end{abstract}

Portanto, nota-se que apesar de toda legislação trabalhista, que põe à disposição do trabalhador um largo leque de direitos e garantias, parte deles sequer pode usufruir das benesses a eles conferidas, pois as altas taxas de desemprego e informalidade crescente simplesmente os excluem da ilha protetiva criada pelo legislador. Em suma, a legislação criada abstratamente, inadequada à realidade fática nacional, não consegue ser alcançada por seus destinatários, que em razão dos motivos acima expostos, ficam à margem dessa proteção. O economista Ladislau Dowbor (2006) entende que "conseguimos avanços muito significativos em termos de leis de proteção do trabalho, de controle do trabalho infantil. No entanto, apenas um terço dos trabalhadores, no Brasil, tem um emprego formal no setor privado, com carteira assinada e direitos assegurados."

Dentro desse contexto, doutrina Robortella (1994, p. 25): “A proteção, quando desgarrada do contexto econômico, corre o risco de transformar-se em desproteção", para ele

esta forma de proteção cegamente concentrada na pessoa do trabalhador - e a crítica se faz à cegueira e não ao destinatário, muitas vezes vítima dela discrepante do contexto social e econômico, produziu uma espécie de fantasia legislativa, com expectativas frustradas ou de impossível realização. (ROBORTELLA, 1994, p. 28). 
Uma ação que efetivamente pode contribuir para a saída desse problema é a criação de uma espécie de "Simples Trabalhista" para reduzir a informalidade, estimular a criação de novos postos de trabalho e proteger, ainda que parcialmente, os trabalhadores. Para tanto, os especialistas no assunto opinam, aos quais uma questão é unânime: as micro e as pequenas empresas sofrem diariamente com a falta de flexibilização da legislação trabalhista.

Dalva Amélia de Oliveira (2003, p. 357-365), Juíza da 73a Vara do Trabalho do Rio de Janeiro, enfrenta a questão observando que "é inquestionável que o Brasil mudou, o mundo mudou e a legislação tem que se adaptar à realidade e tentar solucionar os problemas contemporâneos". Coloca-se, pois, pela introdução de normas trabalhistas que estejam em consonância com o período contemporâneo, para que possam solucionar situações que ora se apresentam à sociedade.

A Câmara Americana de Comércio (AMCHAM, 2006) posiciona-se em prol das seguintes modificações: dilação do período de experiência do funcionário; dispensa do recolhimento do Fundo de Garantia do Tempo de Serviço (FGTS) e a possibilidade de negociação do valor do 13ㅇsalário.

José Pastore é enfático em apoiar a redução da contribuição do FGTS de $8 \%$ para 0,5\% sobre o salário, desde que com expressa concordância do empregado, ou, então, a possibilidade de empresas e empregados poderem negociar o valor da alíquota do FGTS, assim como a negociação e reduções de despesas de contratação. Segundo o mesmo, a rigidez na regulação legal inibe a agilidade dos negócios e a competitividade das empresas e, consequentemente, o emprego e a formalização dos contratos de trabalho (PASTORE, 2005).

A "retipificação do contrato individual do trabalho" é a medida de adaptação à crise da empregabilidade proposta por Renato Rua de Almeida (2000, p. 1249-1254), desde que a promoção do ajustamento da legislação trabalhista contratual não lhe atinja fundamentos dogmáticos, nem modifique sua estrutura normativa.

Iniludivelmente, o panorama econômico e social clama por mudanças na legislação trabalhista. Inevitável será que isso ocorra, mais cedo ou mais tarde, ou quando um governo

8 Luiz Carlos Robortella (1994, p. 113-114) considera “a flexibilização é uma realidade do mercado do trabalho, a exigir o devido diagnóstico da ciência jurídica e, em decorrência, o estudo das soluções normativas adequadas. Não se pode ignorá-la, como se não dissesse respeito ap direito do trabalho. É uma 
Estudo crítico sobre as propostas de alteração do direito do trabalho: tratamento diferenciado aos empregados de microempresas e de empresas de pequeno porte è constitucional e necessário?

preocupado não apenas com o palanque político, mas com as necessidades de seu Estado, o faça ${ }^{9}$.

\subsection{Microempresas e empresas de pequeno porte, trabalhadores e justiça social}

Em que pese as bem-intencionadas sugestões anteriormente expostas, salvo uma ou outra idéia, inevitável é posicionar-se contrariamente as mesmas, que acabam por criar o "empregado de segunda linha".

Ludibria-se aquele que coloca o sonho de uma economia sólida baseada em crescimento econômico puro e simples, porém forjado pelo cerceamento de direitos trabalhistas. Isso porque os custos sociais resultantes, como aumento da exclusão e da desigualdade social, podem ser mais elevados que os reais ganhos e vantagens alcançadas. Seria olvidar as origens do próprio micro e pequeno empreendedor e abraçar a causa capitalista, contudo, sem dela participar.

Reitera-se a inafastável adequação da legislação trabalhista ao cenário econômico e social brasileiro; contudo, tais modificações devem direcionar-se a todos os trabalhadores, não apenas àqueles dos micro e pequenos empreendimentos.

Repetidamente, tem-se afirmado o tratamento diferenciado constitucionalmente conferido às micro e pequenas empresas, bem como a indiscutível proteção que beneficia os trabalhadores. Que tais normas, por serem constitucionais, não se anulam, mas ao contrário, se completam. Nesse passo, direitos dos mesmos não podem ser suprimidos, mas alargados, em busca da justiça social; e a Ordem Econômica tem por fim, justamente, assegurar a todos existência digna, conforme o caput do art. 170 da Constituição Federal.

E, o que seria esse tipo de empregado, aquele denominado de "segunda linha"? Seria o empregado que, unicamente por trabalhar em uma microempresa ou em uma empresa de pequeno porte teria direitos reduzidos. Tal enquadramento implicaria em negarIhe igualdade de direitos conferidos aos demais trabalhadores. Seria desabonar seu trabalho unicamente por estar empregado em uma empresa que galga os primeiros passos e

realidade inafastável, palpitante, que anseia pela intervenção do jurista, dando-lhe o tom, o ritmo e o conteúdo".

9 Não é a proposta de este trabalho ilustrar mudanças na legislação trabalhista, mais conhecida como flexibilização das leis trabalhistas, razão pela qual não se irá aprofundar no assunto. Por isto, também, não foram abordados os inúmeros outros motivos embasadores desta opinião. 
encontra-se, ainda, em estágio de crescimento, ou que simplesmente não cresceu. Seria, também, desprestigiar o valor do emprego ofertado pelas citadas empresas, como se trabalhar para elas fosse uma infortúnio, uma punição.

Igual concepção possui Marcelo Pimentel, ex-Ministro do Trabalho, que além de discordar da criação de direitos diferentes a empregados de acordo com o tamanho de seu empregador, oferta uma sugestão:

\begin{abstract}
A idéia de diferenciar trabalhador de microempresa daqueles que estão nas grandes é de chocante inconstitucionalidade, pois todos são iguais perante a lei. $O$ que é de ser diferenciado é o sistema: o legislado, hoje CLT, a ser substituído por um outro mais contratualizado, constitucionalmente se resguardando os direitos básicos, isonomia, jornada, higiene e segurança do trabalho, preservação dos direitos adquiridos, restrição à dispensa imotivada, justiça especializada, prescrição, decadência etc. o restante poderia ser objeto de negociação, mas não tendo em vista se o empregado é de pequena ou grande empresa, mas sim, se está sindicalizado ou não, se é alfabetizado ou não, isto é, se necessariamente deve ter o manto de proteção do Estado. Aí poderia permanecer uma CLT mais simplificada, mantida a liberdade de associação. [grifado] (PIMENTEL, 2000, p. 172173).
\end{abstract}

Aceitar inelutavelmente aquelas propostas trazidas à baila seria aventurar-se em caminho periclitante e encerrar justamente aquilo que se busca: a igualdade, que é para todos.

Almejar melhores condições às micro e pequenas empresas, apesar de elogiável, não justifica o sacrifício do princípio basilar da igualdade. É preciso harmonizar a ganância pelo aumento da eficiência e da competitividade com os demais objetivos do desenvolvimento.

O que a Constituição Federal busca é justiça social (CF, art. 170). Para tanto, forçoso discorrer, apesar da obviedade, a diferenciação entre o que seja crescimento econômico, que se opera em âmbito quantitativo e é imediatista e o desenvolvimento, cuja órbita se dá na esfera qualitativa, exige critérios qualitativos ao lado de indicadores quantitativos. ${ }^{10}$ Somente com o desenvolvimento nacional, e não meramente crescimento econômico, será

10 "O processo de desenvolvimento deve levar a um salto, e uma estrutura social para outra, acompanhado da elevação do nível econômico e do nível cultural-intelectual comunitário. Daí porque, importando a consumação de mudança de ordem não apenas quantitativa, mas também qualitativa, não pode o desenvolvimento ser confundido com a idéia de crescimento. Este, meramente quantitativo, compreende uma parcela da noção de desenvolvimento." (GRAU, 2005, p. 216). 
possível a construção de uma sociedade livre, justa e solidária, preceituada pelo art. 3으, inciso I, da Constituição Federal.

Reforça-se que criar direitos diferentes a empregados unicamente por o serem de empresas de portes diferentes, fere de morte o princípio da igualdade, há tanto perseguida e poucas vezes alcançada. É de inquestionável obviedade a inconstitucionalidade de normas diferidas a trabalhadores, tomando-se como critério o tamanho da empresa em que trabalha.

Nos relevantes dizeres de Robortella (1994, p. 71): “A proteção social constitui um dos principais objetivos do Estado e, desde que distribuída com sabedoria e responsabilidade, não se incompatibiliza com o desenvolvimento econômico."

Mas, se essas duas figuras - empregado e empregador -, estão constitucionalmente amparadas com trato diferido, se ambas necessitam e proteção, se as grandes geradoras de emprego - as micro e pequenas empresas - não conseguem cumprir as leis trabalhistas e se não é possível tolher direitos dos trabalhadores, o que fazer?

Faz-se indispensável, para tanto, a aplicação de políticas públicas que garantam a paridade diante da dessemelhança existente entre micro, pequenos, médios e grandes empresários, assistindo as menores no desenvolvimento de uma competitividade mais equânime, de modo a superar o imediatismo do crescimento econômico, adquirindo uma perspectiva de longo prazo para o fortalecimento das empresas de micro ou pequeno porte, até o momento em que possam andar com seus próprios pés.

Esse planejamento haverá de conciliar a multiplicidade dos objetivos estatais com a liberdade individual e a legítima representatividade dos grupos de interesses.

A criação do SUPER SIMPLES foi um grande e importante passo em benefício das micro e pequenas empresas no que tange, notadamente, ao aspecto tributário, mas elas ainda necessitam de algo a mais, maior proteção para compensar a fragilidade que possuem frente às demais empresas - as de grande e médio porte.

Se na seara tributária é possível ampliar a condescendência em favor dos micro e pequenos empreendimentos, no setor trabalhista isso não pode ser feito, em prol dos princípios que guarnecem os trabalhadores. Assim, deve-se buscar compensar a pesada legislação trabalhista suportada pelas microempresas e empresas de pequeno porte por 
outras medidas que lhes favoreçam, pois fazer com que as mesmas arquem com toda a carga trabalhista, sem lhes dar algo em troca, é condená-las à morte prematura.

Essas ações justificam-se inicialmente diante da ordem constitucional, que determina o tratamento diferenciado e benéfico às microempresas e empresas de pequeno porte $^{11}$; por outro lado, inegável reconhecer o proeminente papel destas empresas, que cumprem sua função social com a geração de inúmeros postos de trabalho. Proteção a elas significa proteção ao próprio mercado de trabalho.

Assim, pode-se afirmar que a Ordem Econômica deve estar sustentada na promoção da dignidade da pessoa humana, que pode ser conseguida através de ações dirigidas para a concretização dos valores acima mencionados: justiça social, busca do pleno emprego, valor social do trabalho, redução das desigualdades regionais, entre outros objetivos. Incentivos em prol do desenvolvimento econômico que resulte em melhoria das condições de vida das pessoas são passos dados pelo Estado rumo à implementação daqueles valores. ${ }^{12}$

Portando, outra não pode ser a atitude do Estado que não a criação de políticas públicas afirmativas para que se assegure a concreção dos enunciados constitucionais de proteção aos micro e pequenos empreendimentos e aos trabalhadores, em busca da justiça social. Este o desafio apresentado ao desenvolvimento da República Federativa do Brasil.

\subsection{Ações afirmativas}

Do exposto, a ilação mais sensata a ser extraída é que para garantir o tratamento diferenciado e benéfico às micro e pequenas empresas, para o fim de criar empregos e, ao mesmo tempo, garantir os direitos trabalhistas, imprescindível é a atuação estatal na criação de estratégias capazes de amparar essas duas figuras: ações afirmativas em favor dos mais

11 Tendo-se em vista as inúmeras vezes que esse tratamento fora abordado e para evitar a tautologia, tem-se por despiciendo maiores comentários.

12 E forma bastante clara e precisa, Tramontin explana tais idéias: "A verdade é que a nossa Constituição de 1988 estabelece princípios de intervenção do Estado na ordem econômica com a finalidade de promoção de efetiva função social, que é a principal razão da existência constitucional do Estado. Assim, se a intervenção ocorre através da concessão de incentivos a empresas privadas, o fim a ser perseguido deve ser unicamente a promoção dos fundamentos e objetivos da República, consistentes na valorização do homem como razão da existência do Estado, e não para beneficiar os agentes econômicos receptores das benesses públicas que se preocupam exclusivamente com o lucro." (2002, p. 72). 
Estudo crítico sobre as propostas de alteração do direito do trabalho: tratamento diferenciado aos empregados de microempresas e de empresas de pequeno porte è constitucional e necessário?

fracos, de modo a garantir a competitividade genuína, dando-se, então, cumprimento aos preceitos constitucionais apresentados, principalmente, nos arts. 1으, 3으 e 170 .

\subsubsection{Apoio à exploração das vocações locais}

Existem, no Brasil, realidades completamente diferentes em razão de sua imensidão. Cada ponto segue uma cultura e desenvolve meios próprios de subsistência. Desta feita, urge o fomento à pesquisa dos sistemas produtivos locais, das potencialidades do lugar e as formas de sua utilização, respeitando e explorando o que de melhor aquela localidade tem a oferecer, ou seja, articular as próprias forças locais. Sachs (2003, p. 42) denomina esta ação de "estratégia de desenvolvimento territorial".

Pense-se, por exemplo, no artesanato, que pode ser incentivado à produção voltada à exportação e, com a ajuda Estatal, inserir esses produtos em redes multinacionais. Também, poderia ser incentivada a exploração do turismo local; centro cultural, dentre outros.

\subsubsection{Compras públicas}

Criar uma vinculação entre as compras públicas e a participação das microempresas e empresas de pequeno porte nos processos licitatórios, caracterizada pelo tratamento diferenciado e benéfico a elas significa importante impulso para essas empresas.

\subsubsection{Núcleos de capacitação para micro e pequenos empreendedores}

Aqui sobressai a importância da formação de incubadoras de microempresas e empresas de pequeno porte dentro das universidades, como forma de estabelecer pontes entre a pesquisa e o universo dos pequenos empreendimentos.

Exemplo que tem dado bons resultados é a criação de uma empresa júnior dentro de universidades. Nessas empresas, alunos de diversos cursos orientam e dão apoio administrativo, técnico, jurídico e contábil aos iniciantes no empreendedorismo, ao mesmo tempo em que recebem valioso aprendizado.

Resumidamente, utilizar o conhecimento, muitas vezes obsoleto, dos universitários, otimizar as suas idéias para acompanhar e, concomitantemente, estudar casos práticos, 
mobilizando o potencial de pesquisa das universidades e institutos tecnológicos ao redor de programas voltados às necessidades dos micro e pequenos negócios é medida eficaz e altamente produtiva.(ALBERGARIA, 2003, p. 14-18). ${ }^{13}$

\subsubsection{Acesso ao crédito}

Aos micro e pequenos empresários não bastam as idéias, as oportunidades, se thes faltam o capital. Assim, faz-se imprescindível facilitar o acesso ao crédito, bem como disponibilizar maior volume de verba às mesmas.

\subsubsection{Incentivos fiscais}

A tributação, fonte de inúmeras divergências entre o empresariado e Poder Público, mostra-se como excelente instrumento de incentivo aos micro e pequenos negócios. Assim como esses incentivos são concedidos aos grandes e médios empreendimentos, por que não estendê-los aos de menor porte? Estes, assim como aqueles, também estarão vinculados à geração de postos de emprego e comprometidos com a dinamização da economia.

\section{Conclusão}

As micro e pequenas empresas têm se mostrado como importante setor da economia, criando vagas de emprego e dinamizando setores do comércio, prestação de serviços e indústria.

Contudo, tais empresas, em razão do porte que Ihes é peculiar, enfrentam inúmeras adversidades que travam o seu crescimento: concorrência das empresas maiores, carga tributária elevada, dificultoso acesso ao crédito, falta de preparo dos sócios das empresas para administrar o empreendimento, cumprimento da legislação trabalhista, dentre outros.

Em razão da representatividade, bem como da posição fragilizada, a Constituição Federal instituiu a estas empresas um tratamento diferido e mais benéfico, como forma de auxiliá-las a se desenvolverem.

13 “Estágios que utilizam estudantes de graduação como mão-de-obra barata existem aos montes, porém, estágios que introduzam o jovem no meio profissional, com orientação adequada, estão cada vez mais escassos. Nesse cenário, as empresas juniores têm proliferado no Brasil, se apresentando como uma importante alternativa para aproximação do aluno universitário com o mercado de trabalho." (ALBERGARIA, 2003, p. 14-18). 
Estudo crítico sobre as propostas de alteração do direito do trabalho: tratamento diferenciado aos empregados de microempresas e de empresas de pequeno porte è constitucional e necessário?

Para implementação destas diretrizes, contudo, não se faz necessária a supressão de direitos trabalhistas, sob a justificativa de que uma legislação trabalhista menos onerosa beneficiaria as micro e pequenas empresas.

Tal proposta sequer pode ser tida como constitucional, por afrontar o princípio da igualdade.

Assim, como meio de se conceder um trato mais benéfico às empresas de menor porte é atuar na produção de ações afirmativas, em políticas públicas de incentivo a este setor do empresariado.

Tais atitudes consubstanciam o constitucionalmente legislado, não representando isso apenas um crescimento econômico, mas desenvolvimento, pois não se falaria em supressão de direitos trabalhistas. Assim, estimula-se a geração de empregos e renda de uma maneira eficiente e criativa.

Com isso, certamente o custo social será muito menor, para se atingir melhores resultados, e se falar não apenas em crescimento econômico, mas em desenvolvimento social de toda a sociedade.

\section{Referências}

ALBERGARIA, Rafael Villas Boas. Empresa júnior: uma alternativa viável aos programas de estágio.Revista @prender Virtual, Marília,v. 3, n. 05, p. 14-18, set./out. 2003.

ALMEIDA, Renato Rua de. A Pequena Empresa e os Novos Paradigmas do Direito do Trabalho. Revista LTr, São Paulo, v. 64, n. 10, p. 1249-1254, out. 2000.

AMCHAM. Geração de Empregos. 2006. Disponível em: <http://www.amcham.com.br/relgov/integracao_2006/empregos/index_html>. Acesso em: 31 nov. 2006.

DOWBOR, Ladislau. O que Aconteceu com o Trabalho?, 2006. Disponível em: <http://dowbor.org>. Acesso em: 12 abr. 2007.

DUARTE, Ana Maria Benedito; SILVA, Denise Maria Perissini da. Manual das Microempresas e das Empresas de Pequeno Porte. São Paulo: LTr, 2001.

GRAU, Eros Roberto. A Ordem Econômica na Constituição de 1988. 10. ed. São Paulo: Malheiros, 2005. 
IBGE. As Micro e Pequenas Empresas Comerciais e de Serviços no Brasil. 2003. Disponível em: <http://www.ibge.gov.br/home/estatistica/economia/microempresa/default.shtm>. Acesso em: 13 mar. 2007.

MARTINS, Sérgio Pinto. Direito do Trabalho. 19. ed. São Paulo: Atlas, 2004.

MONTAÑO, Carlos. Microempresa na Era da Globalização. 2. ed. São Paulo: Cortez, 2001.

OLIVEIRA, Dalva Amélia de. Por que Flexibilizar a Legislação Trabalhista? Revista Forense, Rio de Janeiro, v. 365, v. 99, p. 357-365, jan./fev. 2003.

PASTORE, José. Legislação Trabalhista, Emprego e Renda: a reforma necessária. 2005. Disponível em: <http://www.josepastore.com.br/artigos/relacoestrabalhistas/244.htm>. Acesso em: 02 jul. 2006.

PIMENTEL, Marcelo. A Reforma da CLT - imposição do progresso. Revista LTr, São Paulo, v. 64, n. 02, p. 172-173, fev. 2000.

ROBORTELLA, Luiz Carlos Amorim. O Moderno Direito do Trabalho. São Paulo: LTr, 1994.

RODRIGUEZ. Américo Plá. Princípios de Direito do Trabalho. 3. ed. atual. São Paulo: LTr, 2000.

SACHS, Ignacy. Inclusão Social pelo Trabalho: desenvolvimento humano, trabalho decente e o futuro dos empreendedores de pequeno porte. Rio de Janeiro: Garamond, 2003.

SEBRAE. MPE em Números. 2004. Disponível em:

<http://www.sebrae.com.br/br/home/index.asp>. Acesso em: 11 mar. 2007.

SILVA, José Afonso da. Curso de Direito Constitucional Positivo. 23. ed. ver. e atual. nos termos da Reforma Constitucional. São Paulo: Malheiros, 2004.

TRAMONTIN, Odair. Incentivos Públicos a Empresas Privadas e Guerra Fiscal. Curitiba: Juruá, 2002. 